\title{
Feng Xiaogang's movie economy operation
}

\author{
Hu Jiachong ${ }^{1, *}$, \\ ${ }^{1}$ Literature of Theatre \& Television, Wuhan University (Wuhan),China \\ 383329861@qq.com
}

\begin{abstract}
China's movie industry has developed rapidly since the new century. Feng Xiaogang's movie market oriented, service to the viewers, in a row to create the myth of domestic movie box office, once beyond the period overseas Hollywood blockbusters. His movie economic operation mechanism is very important and urgent to explore the reform of the film system and promote the development of the Chinese film market.
\end{abstract}

Keywords: Movie; Feng Xiaogang; Movie economy

\section{Introduction}

Feng Xiaogang's movie refers to the movie director Feng Xiaogang. Feng Xiaogang's movie is known for the big box office and high return on investment, once beyond the same period the introduction of overseas Hollywood blockbuster. Table 1 summarizes the director Feng Xiaogang's movie box office, from 1997 "Party A party B" 36 million Yuan at the box office, 1998 "Be there or be square" 43 million Yuan at the box office, 1999 "Endless" 33 million Yuan at the box office, 2002 "Big shot's funeral" 43 million Yuan at the box office to 2003 "Mobile phone" 53 million Yuan at the box office. During this period, Feng Xiaogang's film at the box office showed a steady improvement in the situation. After 2004, director Feng Xiaogang's filming of the movie has a qualitative leap, 2004 "A world without thieves" box office 1.2 billion Yuan, in 2007, he directed "The assembly" the box office to 2.4 billion Yuan, in 2009 the "Non honest do not harass" box office 3 billion Yuan, 2013 director Feng Xiaogang's film "Personal tailor" is up to 7 billion Yuan. Feng Xiaogang's movie from 1997 to 2013 this decade has been a very high box office, which can not be ignored the important reason is that the Feng Xiaogang's film has a set of effective economic operation of the film.

Table 1. Feng Xiaogang's movie box office

\begin{tabular}{l|l|l}
\hline Movie & Release Date & Box office \\
\hline Party A Party B & 1997 & 36 million yuan \\
\hline Be There Or Be Square & 1998 & 43 million yuan \\
\hline Endless & 1999 & 33 million yuan \\
\hline Big Shot's Funeral & 2002 & 43 million yuan \\
\hline Mobile phone & 2003 & 53 million yuan \\
\hline $\begin{array}{l}\text { A World Without } \\
\text { Thieves }\end{array}$ & 2004 & 1.2 billion yuan, \\
\hline $\begin{array}{l}\text { The assembly } \\
\text { Non honest do not } \\
\text { harass }\end{array}$ & 2007 & 2.4 billion yuan \\
\hline Personal tailor & 2013 & 3 billion yuan \\
\hline
\end{tabular}




\section{Feng Xiaogang's movie distribution and marketing}

" Honestly, the film took a long time to sell, this is one of the greatest sorrow. I have always thought that film-shooting process is not very difficult and it's not much pressure for me to finish the film, because I have a few good directors, the issue is the key.Director Feng Xiaogang has been working to establish a set of complete and relatively perfect market issue, in the ten years of the movie business practice formed very characteristics of post marketing promotion, distribution strategy that is a very important link. Feng Xiaogang's film companies collaborated with Columbia Company, Hong Kong Media Asia companies on overseas film distribution, such as "mobile phone", "big shot's funeral" and other films mainly by Columbia in the overseas influence. They sold the distribution rights of "a world without Thieves" and "the banquet" film to the Hong Kong Asia Company in order to obtain huge profits.

The focus of Feng Xiaogang's film company propaganda is in front of the release of a film, with the aid of radio, television, newspapers, magazines, Internet and other media to carry out a large area, all-round, multi-level publicity and cause consumer attention. At the same time, the propaganda side multi-faceted attack using the issuance of posters, set up light box advertising, and theater cooperation in the way of viewing and other awards, for more detailed level to increase the breadth and intensity of the publicity. Finally, the issuer also did not forget to organize the creative personnel in the big screening area to meet with the audience, face to face communication, answered all the questions proposed by the audience, indirect for the film publicity, causing a round of another round of viewing the climax. According to the Feng Xiaogang's movie marketing also often create new styles, in the film prior to tempt the appetite of the audience.

\section{The value of Feng Xiaogang's movies}

Feng Xiaogang's film company was an earlier start to operate the film derivative products business. Feng Xiaogang's film has created a precedent for China's commercial model of soft advertising embedded in the film and played a very good effect. More and more movie and television people and businesses began to pay more attention to the business model of product placement. Table 1 summarizes 2010-2013 Chinese movie product placement advertising revenue,Chinese film product placement advertising market will exceed 1 billion yuan in 2013, is expected to reach 10. 200 million yuan. So implantable advertising implants in the film usually have the following two kinds of:

Figure 1. 2010-2013 Chinese movie product placement advertising revenue

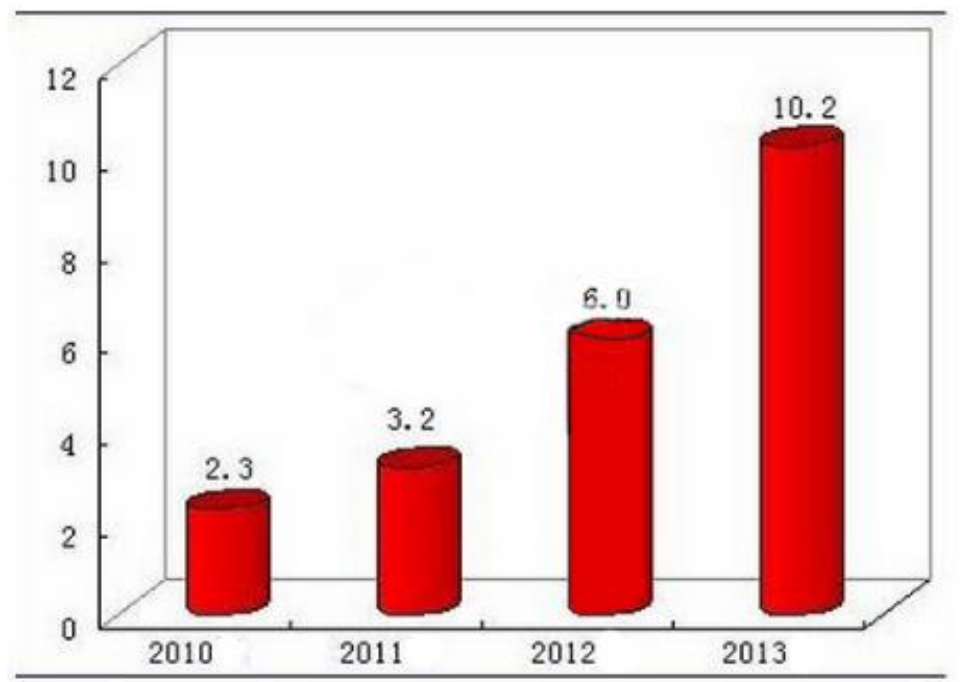

First, props implanted, which is used by the characters in the film for a particular product, and repeated in the film, in order to enhance the number of times to meet with the audience, to deepen the 
memory of the audience on the item. Such as "endless" East China and South Korea to open a bus body advertising, "mobile phone" Motorola and China Telecom, "a world without Thieves" Andy Lau DV, Li Bingbing stolen phone, Zhang Hanyu drawing computer, without exception tried to in the lens show products great brand logo, to "do not sincere non-interference", the whole movie implantable advertising is ubiquitous, such as wine, automotive, cruises, credit card, phone, website, notebook computers, sea view room, scenic spots, such as, movie is not released, the investment has been recovered one greater half.

The second, the scene is implanted. The hotel, hotels, shops and other large construction usually is implanted into the film, you can let the film's protagonist often patronize, or stay in which to start a story.

With advertisers to make up more and more investment in the cost of film investment, which is obvious to save the cost of the film, the key is how to deal with the film in the appropriate product placement advertising. Feng Xiaogang's films meet the maximum business needs of advertisers without affecting the ornamental art. They cleverly implant the product into the plot, and find a balance between commercial and art.

\section{Conclusions}

Movie, as a complete industrial chain including financing, publicity, production, distribution, projection, copyright transactions, film derivative product development, formed the modern film industry and the economy of the film. Study of the economic operation of the film, in fact, mainly related to the film industry chain in the publicity, production, distribution, and other parts of the show, which is far from enough. To change the backward situation the Chinese film in the economic operation, to enter the Chinese film era of prosperity as soon as possible, we need to study the film revenue, the film economy, the improvement of the film industry and the development of the film industry in the process of deepening the reform of the film system In order to promote the development and prosperity of the Chinese film. This is exactly the starting point of the analysis of the economic operation of Feng Xiaogang's movies.

\section{References}

[1] Wang Zhongjun:The experience of "Huayi Brothers". Beijing:China Film Press(2007),p372-376.

[2] Wang Xintao,Chen Xuguang:Feng Xiaogang and "Huayi Brothers ",facing the market of creative arts and creative economy -- Concurrently on the strategy and Its Inspiration to the future development of the Chinese movie. Hangzhou:Journal of Zhejiang University of Media and Communications(2011),p56-63.

[3] Chen Huizhe,Zhang Juping:From "Party A party B" to "The assembly",Feng Xiaogang's movies at the box office. Literature and Art Studies(2008),p50-60. 